\title{
The Possible Mechanisms Involved in the Protection Strategies against Radiation-Induced Cellular Damage by Carnitines
}

\author{
Ashraf Virmani' ${ }^{1}$, Andreas Diedenhofen ${ }^{2}$ \\ ${ }^{1}$ Research, Innovation and Development, Sigma-Tau Health Science International BV, Utrecht, The Netherland \\ ${ }^{2}$ International Division, Sigma-Tau SpA, Rome, Italy \\ Email: ashraf.virmani@sigma-tau.nl
}

Received 18 January 2015; accepted 1 February 2015; published 9 February 2015

Copyright (C) 2015 by authors and Scientific Research Publishing Inc.

This work is licensed under the Creative Commons Attribution International License (CC BY). http://creativecommons.org/licenses/by/4.0/

c) (i) Open Access

\begin{abstract}
There is constant low level background radiation from the cosmos but in certain situation the body may be subjected to increased acute or chronic exposure from other sources. This occurs in situations such as radiation accidents, medical use and could possibly occur in military/terrorist incident. Dependent on the type, strength of the actual source, degree of exposure and type of radiation different strategies may be employed to reduce damage to the body tissues. A number of pharmacological agents such as peroxisome proliferator-activated receptor (PPAR) gamma agonists, diltiazem, amifostine and palifermin as well as antioxidants and metabolic compounds have been shown to be effective in preventing and also in reducing the long-term damage of the exposure of the living cells to radiation. The major drawback of synthetic (pharmacological) compounds has been that they are highly toxic at the optimum protective dose. Studies have shown that various endogenously found compounds such as L-carnitine, and its derivative acetyl-L-carnitine, are able to protect tissues and organs against various forms of toxic insult including radiation damage. The radiation-induced chronic injury may also be counteracted by other metabolic compounds with amine groups and antioxidant properties similar to the carnitines such as cysteine, 3,3'-diindolylmethane (DIM) and $\mathrm{N}$-acetylcysteine. This review discuses the radioprotective compounds as well as the potential mechanism of cellular protection against radiation by carnitines and other compounds.
\end{abstract}

\section{Keywords}

Radiation, L-Carnitine, Acetyl-L-Carnitine, Antioxidants, Mitochondria, DNA 


\section{Types of Radiation and Hazards of Radiation Exposure}

\subsection{Sources of Radiation Exposure}

All living organism from viruses, bacteria to complex plants and animals are subjected to constant background radiation from the earth itself and also from the cosmos (Table 1). In addition, especially in the industrialised coun- tries and war zones there is an increased possibility of exposure to radiation from man-made synthetic or enriched radiation sources (Table 1).

\subsection{Level of Radiation and Type of Damage It Can Provoke}

The damage to living cells depends on the type of radiation (e.g. ionizing or non-ionizing), its strength and degree of exposure. The degree of exposure will depend on the time that the cell or organism is exposed; the distance from the radiation source and whether there is some shielding (lead or other radiation absorbing material) that reduces the degree and strength of exposure. Radiation is known to have powerful carcinogen inducing effects. Indeed there is a close correlation between the level of dose received and the possibility of cancer, which was shown to be dependent quite strongly to the level or dose of radiation [1]. Indeed the exposure of living organisms to nuclear fallout or radioactive isotopes has been shown to result in the accumulation in the body of the radiation source for many years, causing unpredictable chemical and thus biological reactions. This is because the absorption of radiation, especially over prolonged periods of time, can result in free radical damage, mutational damage to DNA, and cellular dysfunction, inducing several disease processes. Symptoms of radiation toxicity in humans include fatigue, migraines, infertility, allergic reactions, hypertension, disorders of the central nervous system, anxiety, memory loss, rheumatic pains, flu-like symptoms, low red and white blood cell counts, in addition to the different types of cancers [1].

\subsection{Ionizing and Non-Ionizing Radiation}

The level of damage will also depend on the type of radiation. There are two types of radiation: ionizing and nonionizing. Both types can be harmful causing DNA damage as well as tissue damage possibly due to the formation of harmful free radicals that can provoke injury or even kill living organisms.

Radiation from certain sources causes the ionization of atoms, hence, the use of the term "ionizing radiation". Ionizing radiation is produced from nuclear reactors, nuclear armaments, nuclear power stations, nuclear medical waste, as well as from diagnostic equipment like X-rays and CT scans. Ionizing radiation is considered the most harmful. This source of radiation energy can also get deposited inside the cell, tissues or material in a fast acute manner or it may accumulate slowly over time. This accumulated radioactive energy would be released and thereby provoke damage. The radiation energy released could excite atoms, molecules, or break molecular bonds within cells and tissues, causing potential damage to the organism. The radiation dose is the measure of the energy deposited inside cells, organs, or body. To measure the energy deposited by the different types of ionizing radiation, a term called "absorbed dose" is used. This term measures the energy deposited by the radiation in one kg of substance. The SI unit of measure is J/kg, which is also called the gray (Gy). Historically a smaller unit was used, called the rad (radiation absorbed dose).

The most common diseases linked to ionizing radiation include thyroid disease, leukemia and various cancers, anemia, bone and blood disorders, endocrine disorders, reproductive abnormalities and birth defects, kidney and liver damage, and also severely compromised immune system.

Table 1. Sources of radiation exposure.

\begin{tabular}{|c|}
\hline Environmental Sources \\
\hline $\begin{array}{ll}\text { - } & \text { Background Cosmic } \\
\text { - } & \text { Background Terrestrial }\end{array}$ \\
\hline Man-Made Synthetic/Enriched Sources \\
\hline $\begin{array}{ll}\text { - } & \text { For Diagnostic and Therapeutic Purposes } \\
\text { - } & \text { For Use in Nuclear Industry } \\
\text { - } & \text { For Use in Military Purposes } \\
\text { - } & \text { For Use in Consumer and Other Purposes }\end{array}$ \\
\hline
\end{tabular}


Non-ionizing radiation is a type of electromagnetic radiation produced by electronic devices such as televisions, cell phones. The effects of this type of radiation are still under study and remain controversial.

\section{Ways to Protect against Radiation-Evoked Cellular Damage}

\subsection{Avoidance and Physical Protection}

As discussed above the biological effects are the result of the dissipation of energy into its interaction with the biological system in the form of ionization and excitation. Thus avoidance and actual physical protection (protective clothing, mask etc.) and other measures to limit exposure are of course the first line of defense against radiation-evoked injury.

\subsection{Pre- and Post-Radiation Exposure Therapy}

However, in many circumstances it is not possible to avoid exposure such as in medical therapy or exposure to radiation accidentally. In this case the biological consequences have to be taken into account. The biological effects could be divided into 2 broad categories:

1. Somatic Effects (e.g. mutations (cancer), or burns, skin loss, cataract);

2. Genetic Effects (e.g. mutations and chromosomal damage).

Over a long term these effects increase the rate of carcinogenesis, cataract formation, cause embryo development issues as well as affect the overall life span of the organism. The type of disease outcome depends generally on the level of tissue sensitivity to radiation damage which can be summarized by the Law of Bergonie' and Tribondeau who said that the level of differentiation of the cells, with the poorly differentiated and rapidly dividing being the most resistant to radiation and that highly differentiated and slowly dividing cells are more resistant to radiation [2].

Taking the above definition into account the tissues that are the most sensitive to radiation damage include the following:

1. Cells in circulation, e.g. blood cells and lymphocytes.

2. The epithelial tissues.

3. Intestinal crypt cells.

4. Cells of the reproductive system, e.g. sperm, oocyte, fetal developing cells.

5. The lens of the eye.

6. Thyroid gland.

\subsection{Protection of Biological Systems from Radiation Damage}

The thyroid gland is particularly susceptible to radiation damage since it accumulates iodine and may therefore accumulate any radioactive iodine following accidental exposure, e.g. in the event of a nuclear accident. In this case potassium iodide pills can be taken to prevent the uptake of radioactive iodine. Supplementing with potassium iodine (KI) in either pill form or saturated liquid form (super saturated potassium iodide or SSKI), is the best way to quickly load iodine into the thyroid. KI can also be administered in prophylactic doses within 24 hours of exposure in case of radiation emergencies.

In the 1940's French researchers, Latarjet and Ephrati, showed that it was actually possible to protect all the biological systems of the body, including all the various tissues and organs, not just the thyroid, from radiationevoked damage [1]. They showed that cysteine and other endogenous thiols similar to cysteine such as cystine, glutathione, thioglycolic acid, and tryptophan were able to protect against harmful radiations (review [2], [3]). The cysteine protected the mice and rats against radiation-induced sickness and mortality. Indeed, further experiments showed that removal of the carboxyl group of cysteine to create 2-mercaptoethylamine (cysteine amine) resulted in a compound that was far more efficacious than the cysteine as a protective agent in the mice [4].

Further research by various groups has shown that pretreatment with other chemical compounds such as 2mercaptopropionylglycine (2-MPG) [5] and S-2-(3-aminopropylamino)-ethylphosphorothioic acid (WR-2721) [6] could also protect animals against the damaging effects of ionizing radiation.

A number of pharmacological compounds have also been shown to have radioprotection properties. Thus diltiazem, acalcium antagonist with a benzothiazepine structure, was found to protect mice against a lethal (LD100) gamma radiation dose allowing a very high number of animals (up to 93\%) to survive [7]. Other compounds, 
amifostine and palifermin, have also been approved for clinical use to protect during radiotherapy of head and neck cancer or during total body irradiation [8].

The major drawback of synthetic (pharmacological) compounds has been that they are highly toxic at the optimum protective dose. Therefore, it is better to use other materials, which are less toxic and offer high protection. Plants and naturally found endogenous molecules such as carnitine have been evaluated as promising sources of radioprotectors because of their low toxicity compared to synthetic thiol compounds and pharmacological agents [9]-[12].

\section{Use of Carnitines and Other Compounds against Radiation-Evoked Cellular Damage}

Carnitine (3-hydroxy-4-N-trimethylammonium butyrate) and its acetylated derivative, acetyl-L-carnitine are compounds that are endogenously found in the body (Figure 1). The L-carnitine is an essential cofactor in the mitochondrial metabolism of fatty acids [13]. The L-carnitine molecule is required for the shuttling of fatty acids across the inner mitochondrial membrane for their use in production of energy via the beta-oxidation pathway and oxidative phosphorylation within the mitochondria. Numerous studies have shown that the carnitines, in particular acetyl-L-carnitine, are able to protect various types of cells of the body that are subjected to different types of insults, ranging from toxic molecules that inhibit the mitochondria to conditions such as ischemia and hypoxia [13]. These protective properties of the carnitines could be related to the pro-energy effects as well as other intrinsic properties such as ability to reduce free radical damage and act as antioxidants. Indeed, other compounds that have amine groups such as cysteine and $\mathrm{N}$-acetylcyteine, as well as antioxidant properties such as Vitamin E and plant extracts have also been shown in preclinical studies to demonstrate protective actions against radiation-induced tissue injury discussed further below.

\subsection{L-Carnitine and Its Derivative Acetyl-L-Carnitine}

Mitochondrial metabolic defects could affect the electron transport, the tricarboxylic acid cycle, and substrate transport. However, it is the escape of oxygen free radicals (superoxide formation) as a result of a disturbed electron transfer within the respiratory chain that is thought to underlie much of the deleterious effects of mitochondrial dysfunction [14].

L-carnitine is found in the blood but it does not bind to plasma proteins (fraction unbound $=1$ ) [15], and enters erythrocytes very slowly [16], which is in keeping with its polar characteristics. A number of studies have shown that the uptake of L-carnitine into most tissues of the body and indeed cell types, including liver, kidney, skeletal and cardiac muscle, and epididymal tissue, involves active carrier-mediated transport systems which maintain high tissue-to-blood concentration ratios [17]-[19]. Primary L-carnitine deficiency has been described due to genetic defect in transport. In a murine model of systemic carnitine deficiency caused by a spontaneous mutation in the mouse, there was fatty microvesicular infiltration of viscera, particularly liver and kidney, hyperammonemia, mitochondrial abnormalities, hypoglycaemia, cardiac hypertrophy and death [20]. The mutation was designated juvenile visceral steatosis (jvs) and was found to be associated with severe systemic carnitine deficiency. Daily administration of L-carnitine started on the tenth day after birth kept the jvs mice alive.<smiles>C[N+](C)(C)CC(O)CC(=O)O</smiles>

L-carnitine<smiles>COC(CC(=O)O)CC(C)(C)C</smiles>

Acetyl-L-carnitine

Figure 1. Structure of L-carnitine and acetyl-L-carnitine. 
Thus, L-carnitine which is an endogenous mitochondriotropic substance is used in therapy to replace depleted levels, resulting in restoration of normal cellular functions and hence maintaining normal body health. Furthermore both L-carnitine and its acetylated form, acetyl-L-carnitine, demonstrate antioxidative properties, protecting cells against lipid peroxidation and membrane breakdown [14] [19]. Research studies, conducted in several in vitro and in vivo animal and clinical models have shown that these agents are active in treatment of abnormal cellular metabolism induced by mitochondrial inhibitors, or those caused by L-carnitine deficiency or insufficiency created by iatrogenic factors (e.g., valproate, pivalic acid). Indeed a number of research studies have also shown that both L-carnitine and acetyl-L-carnitine are able to protect against the damaging effects of radiation.

Studies in preclinical animal models showed the protective effects of the carnitines against exposure of various tissues and organs to different types of ionizing radiation (review [21]) (Table 2). Furthermore, a deficiency in carnitine has been shown to augment even further the toxicity of radiation [21]. In cancer patients receiving radiotherapy, studies have shown that carnitine homeostasis is negatively affected and especially in combination with the toxic side effects chemotherapy, the L-carnitine levels and homeostasis could be further compromised [21].

The study by Dokmeci [22] in an animal model (hamster) showed that L-carnitine pre-treatment $(50 \mathrm{mg} / \mathrm{kg}$, o.s., for 15 consecutive days before 8 Gy irradiation) was effective in significantly reducing peroxidative damage marker malondialdehyde (MDA) in the plasma and liver, improve glutathione (GSH) levels in liver and improve superoxide dismutase (SOD) and catalase activity in red blood cells.

L-carnitine (100 mg/kg/day, i.p.) for 5 days was able to prevent radiation-induced cochlear damage after total cranial irradiation in Guinea pigs [23].

In a rat model of gamma irradiation a single dose to total cranium (IR) led to a significant increase in oral mucositis, MDA levels and a decrease in superoxide dismutase (SOD) and catalase (CAT) activities [24]. The thrombocyte and white blood cell counts in plasma were also reduced. All these changes were found to be counteracted by the administration of L-carnitine $200 \mathrm{mg} / \mathrm{kg} /$ day, i.p. $4 \mathrm{~h}$ before irradiation until 10 days after irradiation [24].

L-carnitine $100 \mathrm{mg} / \mathrm{kg}$, i.p. pre- and post-treatment (1 day before irradiation and for $10 \mathrm{~d}$ after) was found to protect against the radiation-induced cataracts in lens in rats [25]. The treatment with L-carnitine was also shown to decrease MDA level and to increase SOD and glutathione peroxidase activity [25]. The protection to the eye retina was shown by L-carnitine $200 \mathrm{mg} / \mathrm{kg} /$ day, i.p. following irradiation [26]. The radiation-induced damage to brain as well as the increase in MDA and decrease in SOD and catalase enzymes in the brain was also significantly counteracted by the L-carnitine treatment [26].

L-carnitine was able to prevent gamma radiation damage in active tissue with rapidly dividing cells like the seminiferous tubules [27]. The histopathological findings showed that treatment resulted in seminiferous tubules

Table 2. Preclinical studies showing the protective effects of L-carnitine and acetyl-L-carnitine against radiation-induced tissue damage.

\begin{tabular}{|c|c|c|}
\hline \multicolumn{3}{|c|}{ Preclinical model of protection against ionizing radiation } \\
\hline Compound & Tissue/Organ Examined & Reference \\
\hline \multirow[t]{9}{*}{ L-carnitine } & Plasma, liver and erythrocytes & Dokmeci et al., 2006 [22] \\
\hline & Cochlear damage & Altas et al., 2006 [23] \\
\hline & Oral mucositis and myelosuppression & Ucuncu et al., 2006 [24] \\
\hline & Eye cataracts & Kocer et al., 2007 [25] \\
\hline & Brain and retinal damages & Sezen et al., 2008 [26] \\
\hline & Testis-seminiferous tubules damage & Topcu-Tarladacalisir et al., 2009 [27] \\
\hline & Testicular damage & Kanter et al., 2010 [28] \\
\hline & Kidney damage & Caloglu et al., 2009, Cosar et al., 2011 [29] [30] \\
\hline & Ileal mucosal injury & Caloglu et al., 2012 [31], Akpolat et al., 2013 [32] \\
\hline \multirow[t]{2}{*}{ Acetyl-L-carnitine } & Lung and liver & Mansour, 2006 [33] \\
\hline & Whole body effects and mortality & Babicová et al., 2013 [34] \\
\hline
\end{tabular}


with relatively normal structure and resumption of complete spermatogenesis after 21 days [27]. In a further study this group [28] showed that L-carnitine treatment significantly attenuated the radiation-induced morphological changes and germ cell apoptosis in the irradiated rat testis.

Another organ that was found to be protected against radiation-induced damage was the kidney [29] [30]. This histopathological studyshowed that L-carnitine $300 \mathrm{mg} / \mathrm{kg}$, i.p. was able to attenuate damage to the kidney in particular the proximal tubular damage in infant (still developing) rats [29] [30].

The administration of L-carnitine (300 $\mathrm{mg} / \mathrm{kg}$ ) given $30 \mathrm{~min}$ beforetotal abdomen irradiation was found to partially protect against acute small intestinal toxicity having effect mainly on the vascular structure [31]. The ileal mucosal injury in the rat followingwhole-body $\mathrm{X}$-irradiation was also shown to be protected by L-carnitine $200 \mathrm{mg} / \mathrm{kg}$ LC [32]. The L-carnitine was given one day before and for four days after irradiationin this study [32]. The levels of serum monocyte chemotactic protein-1 (MCP-1) and interferon gamma (IFN- $\gamma$ ) were significantly increased by the radiation and this was also counteracted by the L-carnitine treatment [32].

The acetylated derivative of L-carnitine, acetyl-L-carnitine $(250 \mathrm{mg} / \mathrm{kg}$, i.p. for 5 consecutive days and $1 \mathrm{~h}$ after the last dose) was also found to be effective in gamma-irradiation-induced oxidative damage in liver and lung tissue after total body irradiation with a single dose [33]. Administration of acetyl-L-carnitine also resulted in a significant increase in the activities of SOD and glutathione peroxidase, as well as the level of reduced glutathione in these tissues these were reduced by radiation treatment. Treatment also resulted in a significant decrease in total nitrate/nitrite and MDA levels in both tissues [34]. Similar protective effects with acetyl-L-carnitine were seen in rats following whole body radiation [34]. The acetyl-L-carnitine was administered at 250 $\mathrm{mg} / \mathrm{kg}$, i.p., once daily for five days and was able to prevent the radiation-induced increase in plasma MDA and it also reduced 2.6-fold the risk for death during the subsequent 30-day period [34].

\subsection{Other Protective Compounds}

Various other compounds with putative antioxidant and metabolic activity have also been reported to be effective in protecting against radiation-induced chronic injury [4] [35]. For example, studies have shown that radioprotection is seen with Vitamin E [36] [37], lipoic acid, 3,3'-diindolylmethane (DIM) [38], N-acetylcysteine [39], glutathione (GSH) [40], melatonin [37] [41] as well as other compounds [4] [35].

A number of compounds from plants sources have been shown to be effective radioprotectors [42]-[45]. These include turmeric [43], Rosemarinus officinalis extract [45], ginkgo biloba [46], and other compounds [42]-[45].

\section{Mechanism of Cellular Protection}

As mentioned before the mechanism underlying ionizing radiation-induced damage has a lot in common with other metabolic stress and age-related disease processes [13]. The underlying mechanism in most cases is oxidative stress and metabolic dysfunction that leads to the damage to the major cell structural and functional components, in particular to the proteins, lipids and the DNA, this in turn manifests as cell injury [13] [47].

Thus protective strategies concentrate on compounds able to:

1) Protect against protein misfolding and enhancing DNA repair;

2) Protect against cellular and organelle damage by antioxidants;

3) Protect and enhance mitochondrial energy production.

\subsection{Protection against Protein Misfolding and Enhancing DNA Repair}

Radiation is a phenomenon that has influenced life on earth since its evolution. Indeed nature has found various strategies to limit its damaging effects in all living organisms. The extreme form of this protective strategy is seen in certain strains of bacteria. For example in Deinococcus radiodurans and other bacteria which are extremely resistant to ionizing radiation as well ultraviolet radiation [48]. Indeed in latin, radius and durare mean "radiation surviving" and this organism can survive an acute dose of $5000 \mathrm{~Gy}$ (500,000 rad) of ionizing radiation and just for comparison, a chest X-ray or Apollo mission is around $1 \mathrm{mGy}$ and a dose of 5 Gy will kill a human being.

The Deinococcus radiodurans achieves its remarkable resistance to these extreme levels of radiation by having multiple copies of its genome and by having rapid and highly efficient DNA repair mechanisms. It is the unrepaired DNA double-strand breaks (DSBs) that are thought to be the main the cause of ionizing radiation- 
induced cell-killing. This gives the Deinococcus radiodurans and other organisms from this genus the extraordinary resistance to the lethal and mutagenic effects of ionizing and u.v. radiation and to many other agents that are toxic via DNA damage. However, it has been shown that there is large variation in radiosensitivity among bacterial species which correlates not to the initial damage to the DNA but rather with the susceptibility of their proteins to radiation-induced oxidation and the actual resulting extent of protein damage [49]. Thus level of protein damage in irradiated cells is strongly correlated to their antioxidant status [49].

In case of the actual protein the oxidation and/or resulting misfolding not only creates functional issues, for example if it is an enzyme or transporter protein it will not be able to carry out its function, but may transform certain proteins into more toxic forms [50] [51]. Indeed in this situation the cellular antioxidant defences are critical and the carnitines have been shown to increase these as mentioned above. Furthermore the acetyl-L-carnitine has been shown before to protect against the toxicity to aberrant proteins such as amyloid proteins which are thought to provoke brain damage in certain neurodegenerative disease such as Alzheimer’s [50].

\subsection{Protection against Cellular and Organelle Damage by Antioxidants}

Many studies have shown that both L-carnitine and acetyl-L-carnitine are able to reduce the damage to the lipids due to peroxidation and thereby reduce the radiation-evoked MDA generation. They also increase the levels of the intracellular antioxidant enzymes, SOD and glutathione and catalase. Both compounds have been reported to possess antioxidant properties but in particular they reduce the generation and the release of the extremely toxic free radicals from the mitochondria that is increased when the respiratory chain in the mitochondria and the mitochondrial membranes are compromised [13] [14] [52].

\subsection{Mitochondrial Energy Production}

Most of the cellular energy in eukaryotic cells comes from the generation of high energy phosphate bonds in the form of adenosine triphosphate (ATP) and the most amount of cellular ATP is generated within the mitochondria. The net amount of energy equivalents to be obtained from a molecule of glucose is about 30 ATP whereas the beta oxidation of a fatty acid like palmitate produces 106 ATP. For beta oxidation of the fatty acids the molecule of fatty acid has to first be transported across the inner mitochondrial membrane and this can only occur in the presence of L-carnitine which actually binds to the fatty acids thereby permitting its movement into the mitochondria. Thus, although L-carnitine is a relatively simple molecule, it can greatly influence cellular energy production by facilitating beta-oxidation [13] [14] [52].

\section{Future Strategies for Protection against Radiation}

In recent years studies have shown that the cellular damage induced by radiation can be reduced by using particular compounds. Strategies are being developed to protect tissues and organisms not only from accidental radiation exposure such as in possible war or terrorist attack but also from pathological changes induced in normal tissues following radiotherapy for cancer [53]-[55]. A number of these compounds have antioxidant properties whereby they protect the cellular lipids, proteins and particularly the DNA from radiation damage. These compounds exert their radioprotection through antioxidant and free radical-scavenging activities [9] [21]. In particular the carnitines, L-carnitine and acetyl-L-carnitine, have been shown not only to have protective abilities per se [13] [14] [50] but also to increase the endogenous cellular antioxidant defense mechanisms thereby protecting the organism from radiation-induced cellular and organ toxicity [9] [21].

Another common side effect of radiation exposure and especially in cancer therapy is fatigue [9] [21]. Studies are showing that this can be improved by the treatment with L-carnitine [56]. This study showed that L-carnitine administration reduced fatigue and improved quality of life in 12 advanced cancer patients undergoing anticancer therapy [56]. This study also showed that the levels of reactive oxygen species were decreased and level of glutathione peroxidase was increased but possibly due to the low number of subjects did not reach significance.

\section{Conclusion}

Strategies exist for counteracting the damaging effects to either accidental or therapeutic exposure to radiation. These include the administration of protective compounds such as L-carnitine and acetyl-L-carnitine as well as other compounds. The replenishing the carnitine pool by systemic administration of L-carnitine has been found 
to be beneficial in reducing the side effects of radio chemotherapy [9] [21]. However, more controlled studies especially in models that better reflect the situation in humans and clinical situations are necessary. The intrinsic properties of L-carnitine and acetyl-L-carnitine as therapeutic and defensive agents against accidental exposure to radiation need to be examined further to find the best dosage and whether administration together improves efficacy. The role of radiation in aging and age-related disease processes in general has been largely ignored but future studies should also look at this.

\section{Acknowledgements}

We are grateful to Mrs. Antoinette Celli for her help with the grammatical revision of the manuscript.

\section{References}

[1] Laterjet, R. and Ephrati, E. (1948) Influence protectrice de certaines substance contrel' inactivationd' um bacteriophage par les rayons X. Comptes Rendus des Séances de la Société de Biologie et de Ses Filiales, 142, 497-499

[2] Joshi, Y., Jadhav, T. and Kadam, V. (2010) Radioprotective-A Pharmacological Intervention for Protection against Ionizing Radiations: A Review. The Internet Journal of Internal Medicine, 8, 2.

[3] Hosseinimehr, S.J. (2007) Trends in the Development of Radioprotective Agents. Drug Discovery Today, 12, $794-805$. http://dx.doi.org/10.1016/j.drudis.2007.07.017

[4] Weiss, J.F. and Landauer, M.R. (2003) Protection against Ionizing Radiation by Antioxidant Nutrients and Phytochemicals. Toxicology, 189, 1-20. http://dx.doi.org/10.1016/S0300-483X(03)00149-5

[5] Sugahara, T., Tanaka, Y., Nagata, H., Tanaka, T. and Kano, E. (1970) Radiation Protection by 2-Mercaptopropionylglycine. Proceedings of the International Symposium on Thiola, Osaka, 267-272.

[6] Yuhas, J.M. (1980) Active versus Passive Absorption Kinetics as the Basis for Selective Protection of Normal Tissues by S-2-(3-Aminopropylamino)-Ethylphosphorothioic Acid. Cancer Research, 40, 1519-1524.

[7] Nunia, V. and Goyal, P.K. (2004) Prevention of Gamma Radiation Induced Anaemia in Mice by Diltiazem. Journal of Radiation Research, 45, 11-17. http://dx.doi.org/10.1269/jrr.45.11

[8] Maier, P., Wenz, F. and Herskind, C. (2014) Radioprotection of Normal Tissue Cells. Strahlentherapie Und Onkologie, 190, 745-752. http://dx.doi.org/10.1007/s00066-014-0637-x

[9] Kuntić, V.S., Stanković, M.B., Vujić, Z.B., Brborić, J.S. and Uskoković-Marković, S.M. (2013) Radioprotectors-The Evergreen Topic. Chemistry \& Biodiversity, 10, 1791-1803. http://dx.doi.org/10.1002/cbdv.201300054

[10] Citrin, D., Cotrim, A.P., Hyodo, F., Baum, B.J., Krishna, M.C. and Mitchell, J.B. (2010) Radioprotectors and Mitigators of Radiation-Induced Normal Tissue Injury. Oncologist, 15, 360-371. http://dx.doi.org/10.1634/theoncologist.2009-S104

[11] Weiss, J.F. and Landauer, M.R. (2003) Protection against Ionizing Radiation by Antioxidant Nutrients and Phytochemicals. Toxicology, 189, 1-20. http://dx.doi.org/10.1016/S0300-483X(03)00149-5

[12] Jagetia, G.C. (2007) Radioprotective Potential of Plants and Herbs against the Effects of Ionizing Radiation. Journal of Clinical Biochemistry and Nutrition, 40, 74-81. http://dx.doi.org/10.3164/jcbn.40.74

[13] Virmani, A. and Binienda, Z. (2004) Role of Carnitine Esters in Brain Neuropathology. Molecular Aspects of Medicine, 25, 533-549. http://dx.doi.org/10.1016/j.mam.2004.06.003

[14] Virmani, A., Pinto, L., Binienda, Z. and Ali, S. (2013) Food, Nutrigenomics, and Neurodegeneration-Neuroprotection by What You Eat! Molecular Neurobiology, 48, 353-362. http://dx.doi.org/10.1007/s12035-013-8498-3

[15] Marzo, A., Arrigoni Martelli, E., Mancinelli, A., Cardace, G., Corbelletta, C., Bassani, E. and Solbiati, M. (1991) Protein Binding of L-Carnitine Family Components. European Journal of Drug Metabolism and Pharmacokinetics, Special Issue III, 364-368.

[16] Baker, H., Frank, O., De Angelis, B. and Baker, E.R. (1993) Absorption and Excretion of L-Carnitine during Single or Multiple Dosing in Humans. International Journal for Vitamin and Nutrition Research, 63, 22-26.

[17] Rebouche, C.J. (1986) Recent Advances in Carnitine Biosynthesis and Transport. In: Borum, P.R., Ed., Clinical Aspects of Human Carnitine Deficiency, Pergamon, New York, 1-15.

[18] Brass, E.P. (1992) Carnitine Transport. In: Ferrari, R., DiMauro, S. and Sherwood, G., Eds., L-Carnitine and Its Role in Medicine: From Function to Therapy, Academic Press Limited, London, 21-36.

[19] Virmani, M.A., Rossi, S., Conti, R., Spadoni, A., Arrigoni-Martelli, E. and Calvani, M. (1996) Structural, Metabolic and Ionic Requirements for the Uptake of L-Carnitine by Primary Rat Cortical Cells. Pharmacological Research, 33, 19-27. http://dx.doi.org/10.1006/phrs.1996.0004 
[20] Kuwajima, M., Kono, N., Horiuchi, M., Imamura, Y., Ono, A., Inui, Y., Kawata, S., Koizumi, T., Hayakawa, J., Saheki, T., et al. (1991) Animal Model of Systemic Carnitine Deficiency: Analysis in C3H-H-2 ${ }^{\circ}$ Strain of Mouse Associated with Juvenile Visceral Steatosis. Biochemical and Biophysical Research Communications, 174, 1090-1094. http://dx.doi.org/10.1016/0006-291X(91)91532-H

[21] Khan, H.A. and Alhomida, A.S. (2011) A Review of the Logistic Role of L-Carnitine in the Management of Radiation Toxicity and Radiotherapy Side Effects. Journal of Applied Toxicology, 31, 707-713. http://dx.doi.org/10.1002/jat.1716

[22] Dokmeci, D., Akpolat, M., Aydogdu, N., Uzal, C., Doganay, L., Turan, F.N. and Mansour, H.H. (2006) The Protective Effect of L-Carnitine on Ionizing Radiation-Induced Free Oxygen Radicals. Scandinavian Journal of Laboratory Animal Science, 33, 75-83.

[23] Altas, E., Ertekin, M.V., Gundogdu, C. and Demirci, E. (2006) L-Carnitine Reduces Cochlear Damage Induced by Gamma Irradiation in Guinea Pigs. Annals of Clinical and Laboratory Science, 36, 312-318.

[24] Uçüncü, H., Ertekin, M.V., Yörük, O., Sezen, O., Ozkan, A., Erdoğan, F., Kiziltunç, A. and Gündoğdu, C. (2006) Vitamin E and L-Carnitine, Separately or in Combination, in the Prevention of Radiation-Induced Oral Mucositis and Myelosuppression: A Controlled Study in a Rat Model. Journal of Radiation Research, 47, 91-102. http://dx.doi.org/10.1269/jrr.47.91

[25] Kocer, I., Taysi, S., Ertekin, M.V., Karslioglu, I., Gepdiremen, A., Sezen, O. and Serifoglu, K. (2007) The Effect of L-Carnitine in the Prevention of Ionizing Radiation-Induced Cataracts: A Rat Model. Graefe's Archive for Clinical and Experimental Ophthalmology, 245, 588-594. http://dx.doi.org/10.1007/s00417-005-0097-1

[26] Sezen, O., Ertekin, M.V., Demircan, B., Karslioğlu, I., Erdoğan, F., Koçer, I., Calik, I. and Gepdiremen, A. (2008) Vitamin E and L-Carnitine, Separately or in Combination, in the Prevention of Radiation-Induced Brain and Retinal Damages. Neurosurgical Review, 31, 205-213. http://dx.doi.org/10.1007/s10143-007-0118-0

[27] Topcu-Tarladacalisir, Y., Kanter, M. and Uzal, M.C. (2009) Role of L-Carnitine in the Prevention of Seminiferous Tubules Damage Induced by Gamma Radiation: A Light and Electron Microscopic Study. Archives of Toxicology, 83, 735-746. http://dx.doi.org/10.1007/s00204-008-0382-y

[28] Kanter, M., Topcu-Tarladacalisir, Y. and Parlar, S. (2010) Antiapoptotic Effect of L-Carnitine on Testicular Irradiation in Rats. Journal of Molecular Histology, 41, 121-128. http://dx.doi.org/10.1007/s10735-010-9267-5

[29] Caloglu, M., Yurut-Caloglu, V., Durmus-Altun, G., Oz-Puyan, F., Ustun, F., Cosar-Alas, R., Saynak, M., Parlar, S., Turan, F.N. and Uzal, C. (2009) Histopathological and Scintigraphic Comparisons of the Protective Effects of L-Carnitine and Amifostine against Radiation-Induced Late Renal Toxicity in Rats. Clinical and Experimental Pharmacology and Physiology, 36, 523-530. http://dx.doi.org/10.1111/j.1440-1681.2008.05103.x

[30] Cosar, R., DurmusAltun, G., Oz Puyan, F., Saynak, M., Ibis, K., Özen, A., Bayir-Angin, G., Ustun, F., Denizli, B., Parlar, S., Caloglu, M., Yurut-Caloglu, V., Uzal, M.C. and Koçak, Z. (2011) Protective Role of Carnitine against Radiation-Induced Kidney Damage in Infant Rats: Scintigraphic and Histopathologic Evaluation. Radiotherapy and Oncology, 98, S20-S21. http://dx.doi.org/10.1016/S0167-8140(11)71749-2

[31] Caloglu, M., Caloglu, V.Y., Yalta, T., Yalcin, O. and Uzal, C. (2012) The Histopathological Comparison of L-Carnitine with Amifostine for Protective Efficacy on Radiation-Induced Acute Small Intestinal Toxicity. Journal of Cancer Research and Therapeutics, 8, 260-265. http://dx.doi.org/10.4103/0973-1482.98982

[32] Akpolat, M., Gulle, K., Topcu-Tarladacalisir, Y., Safi Oz, Z., Bakkal, B.H., Arasli, M. and Ozel Turkcu, U. (2013) Protection by L-Carnitine against Radiation-Induced Ileal Mucosal Injury in the Rat: Pattern of Oxidative Stress, Apoptosis and Cytokines. International Journal of Radiation Biology, 89, 732-740.

http://dx.doi.org/10.3109/09553002.2013.787176

[33] Mansour, H.H. (2006) Protective Role of Carnitine Ester against Radiation-Induced Oxidative Stress in Rats. Pharmacological Research, 54, 165-171. http://dx.doi.org/10.1016/j.phrs.2006.04.003

[34] Babicová, A., Havlínová, Z., Hroch, M., Rezáčová, M., Pejchal, J., Vávrová, J. and Chládek, J. (2013) In Vivo Study of Radioprotective Effect of NO-Synthase Inhibitors and Acetyl-L-Carnitine. Physiological Research, 62, 701-710.

[35] Jagetia, G.C., Baliga, M.S., Aruna, R., Rajanikant, G.K. and Jain, V. (2003) Effect of Abana (a Herbal Preparation) on the Radiation-Induced Mortality in Mice. Journal of Ethnopharmacology, 86, 159-165. http://dx.doi.org/10.1016/S0378-8741(03)00037-0

[36] Singh, V.K., Shafran, R.L., Jackson III, W.E., Seed, T.M. and Kumar, K. (2006) Induction of Cytokines by Radioprotective Tocopherol Analogs. Experimental and Molecular Pathology, 81, 55-61. http://dx.doi.org/10.1016/j.yexmp.2005.11.002

[37] Yilmaz, S. and Yilmaz, E. (2006) Effects of Melatonin and Vitamin E on Oxidative-Antioxidative Status in Rats Exposed to Irradiation. Toxicology, 222, 1-7. http://dx.doi.org/10.1016/j.tox.2006.02.008

[38] Fan, S., Meng, Q., Xu, J., Jiao, Y., Zhao, L., Zhang, X., Sarkar, F.H., Brown, M.L., Dritschilo, A. and Rosen, E.M. 
(2013) DIM (3,3'-Diindolylmethane) Confers Protection against Ionizing Radiation by a Unique Mechanism. Proceedings of the National Academy of Sciences of the United States of America, 110, 18650-18655. http://dx.doi.org/10.1073/pnas.1308206110

[39] Mansour, H.H., Hafez, H.F., Fahmy, N.M. and Hanafi, N. (2008) Protective Effect of N-Acetylcysteine against Radiation Induced DNA Damage and Hepatic Toxicity in Rats. Biochemical Pharmacology, 75, 773-780. http://dx.doi.org/10.1016/j.bcp.2007.09.018

[40] Sert, C., Celik, M.S., Akdag, Z., Ketani, M.A. and Nergiz, Y. (2000) The Radioprotective Effect of Vitamins C, E and Vitamin E + Glutathione on the Small Intestine and the Thyroid Gland in Rats Irradiated with X Rays. Turkish Journal of Medical Sciences, 30, 417-425.

[41] Vijayalaxmi, Reiter, R.J., Tan, D.X., Herman, T.S. and Thomas Jr., C.R. (2004) Melatonin as a Radioprotective Agent: A Review. International Journal of Radiation Oncology*Biology*Physics, 59, 639-653. http://dx.doi.org/10.1016/j.ijrobp.2004.02.006

[42] Prasad, K.N. (2005) Rationale for Using Multiple Antioxidants in Protecting Humans against Low Doses of Ionizing Radiation. British Journal of Radiology, 78, 485-492. http://dx.doi.org/10.1259/bjr/87552880

[43] Bhartiya, U.S., Raut, Y.S., Joseph, L.J., Hawaldar, R.W. and Rao, B.S. (2008) Evaluation of the Radioprotective Effect of Turmeric Extract and Vitamin E in Mice Exposed to Therapeutic Dose of Radioiodine. Indian Journal of Clinical Biochemistry, 23, 382-386. http://dx.doi.org/10.1007/s12291-008-0084-5

[44] Samarth, R.M., Panwar, M., Kumar, M., Soni, A., Kumar, M. and Kumar, A. (2008) Evaluation of Antioxidant and Radical-Scavenging Activities of Certain Radioprotective Plant Extracts. Food Chemistry, 106, 868-873. http://dx.doi.org/10.1016/j.foodchem.2007.05.005

[45] Soyal, D., Jindal, A., Singh, I. and Goyal, P.K. (2007) Modulation of Radiation-Induced Biochemical Alterations in Mice by Rosemary (Rosemarinus officinalis) Extract. Phytomedicine, 14, 701-705. http://dx.doi.org/10.1016/j.phymed.2006.12.011

[46] Sener, G., Kabasakal, L., Atasoy, B.M., Erzik, C., Velioğlu-Oğünç, A., Cetinel, S., Gedik, N. and Yeğen, B.C. (2006) Ginkgo Biloba Extract Protects against Ionizing Radiation-Induced Oxidative Organ Damage in Rats. Pharmacological Research, 53, 241-252. http://dx.doi.org/10.1016/j.phrs.2005.11.006

[47] Azzam, E.I., Jay-Gerin, J.P. and Pain, D. (2012) Ionizing Radiation-Induced Metabolic Oxidative Stress and Prolonged Cell Injury. Cancer Letters, 327, 48-60. http://dx.doi.org/10.1016/j.canlet.2011.12.012

[48] Cox, M.M. and Battista, J.R. (2005) Deinococcus radiodurans-The Consummate Survivor. Nature Reviews Microbiology, 3, 882-892. http://dx.doi.org/10.1038/nrmicro1264

[49] Daly, M.J. (2009) A New Perspective on Radiation Resistance Based on Deinococcus radiodurans. Nature Reviews Microbiology, 7, 237-245. http://dx.doi.org/10.1038/nrmicro2073

[50] Virmani, M.A., Caso, V., Spadoni, A., Russo, F., Rossi, S. and Gaetani, F. (2001) The Action of Acetyl-l-Carnitine on the Neurotoxicity Evoked by Amyloid Fragments on Primary Rat Cortical Neurones. Annals of the New York Academy of Sciences, 939, 162-178. http://dx.doi.org/10.1111/j.1749-6632.2001.tb03623.x

[51] Stadtman, E.R. (2006) Protein Oxidation and Aging. Free Radical Research, 40, 1250-1258. http://dx.doi.org/10.1080/10715760600918142

[52] Virmani, M.A., Bisselli, R., Spadoni, A., Rossi, S., Corsico, N., Calvani, M., Fattorossi, A., De Simone, C. and Arrigoni-Martelli, E. (1995) Protective Actions of L-Carnitine and Acetyl-L-Carnitine on the Neurotoxicity Evoked by Mitochondrial Uncoupling or Inhibitors. Pharmacological Research, 32, 383-389. http://dx.doi.org/10.1016/S1043-6618(05)80044-1

[53] Rezvani, M. (2008) Amelioration of the Pathological Changes Induced by Radiotherapy in Normal Tissues. Journal of Pharmacy and Pharmacology, 60, 1037-1048. http://dx.doi.org/10.1211/jpp.60.8.0010

[54] Zhao, W. and Robbins, M.E. (2009) Inflammation and Chronic Oxidative Stress in Radiation-Induced Late Normal Tissue Injury: Therapeutic Implications. Current Medicinal Chemistry, 16, 130-143. http://dx.doi.org/10.2174/092986709787002790

[55] Stone, H.B., McBride, W.H. and Coleman, C.N. (2002) Modifying Normal Tissue Damage Postirradiation. Report of a Workshop Sponsored by the Radiation Research Program, National Cancer Institute, Bethesda, Maryland, 6-8 September 2000. Radiation Research, 157, 204-223. http://dx.doi.org/10.1667/0033-7587(2002)157[0204:MNTDP]2.0.CO;2

[56] Gramignano, G., Lusso, M.R., Madeddu, C., Massa, E., Serpe, R., Deiana, L., Lamonica, G., Dessì, M., Spiga, C., Astara, G., Macciò, A. and Mantovani, G. (2006) Efficacy of L-Carnitine Administration on Fatigue, Nutritional Status, Oxidative Stress, and Related Quality of Life in 12 Advanced Cancer Patients Undergoing Anticancer Therapy. Nutrition, 22, 136-145. http://dx.doi.org/10.1016/j.nut.2005.06.003 
Scientific Research Publishing (SCIRP) is one of the largest Open Access journal publishers. It is currently publishing more than 200 open access, online, peer-reviewed journals covering a wide range of academic disciplines. SCIRP serves the worldwide academic communities and contributes to the progress and application of science with its publication.

Other selected journals from SCIRP are listed as below. Submit your manuscript to us via either submit@scirp.org or Online Submission Portal.
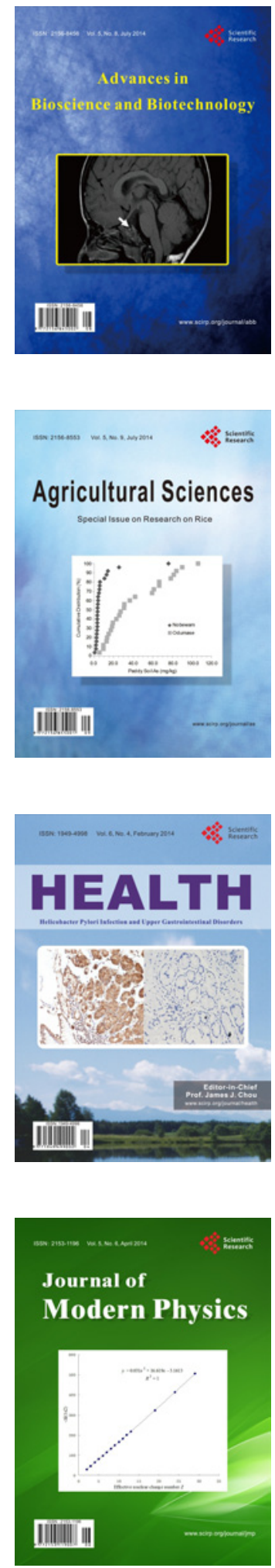
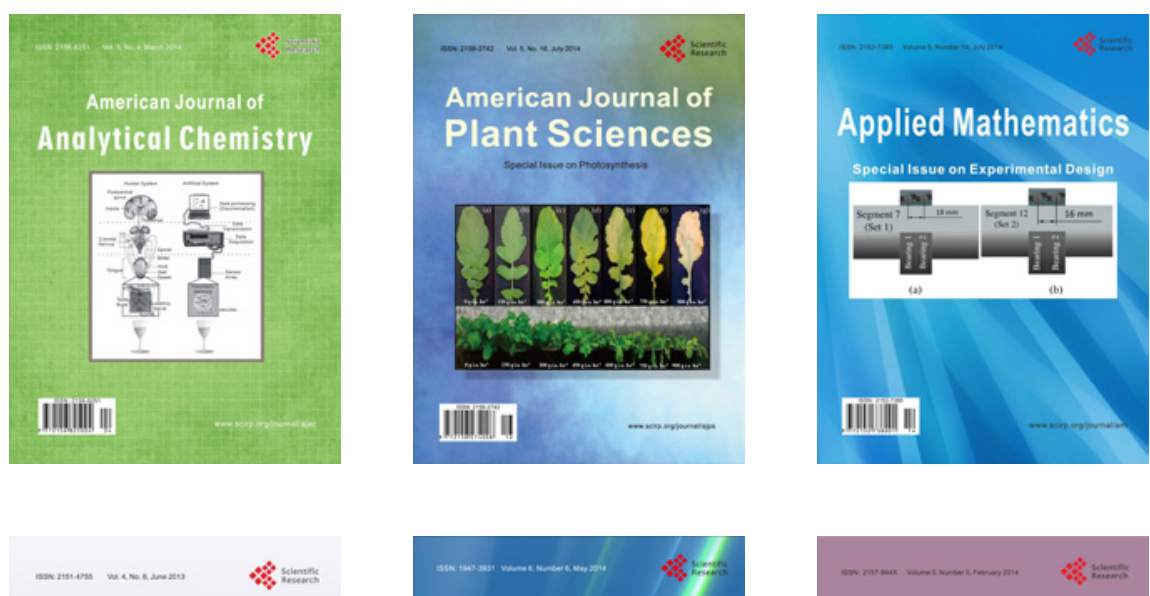

Creative Education
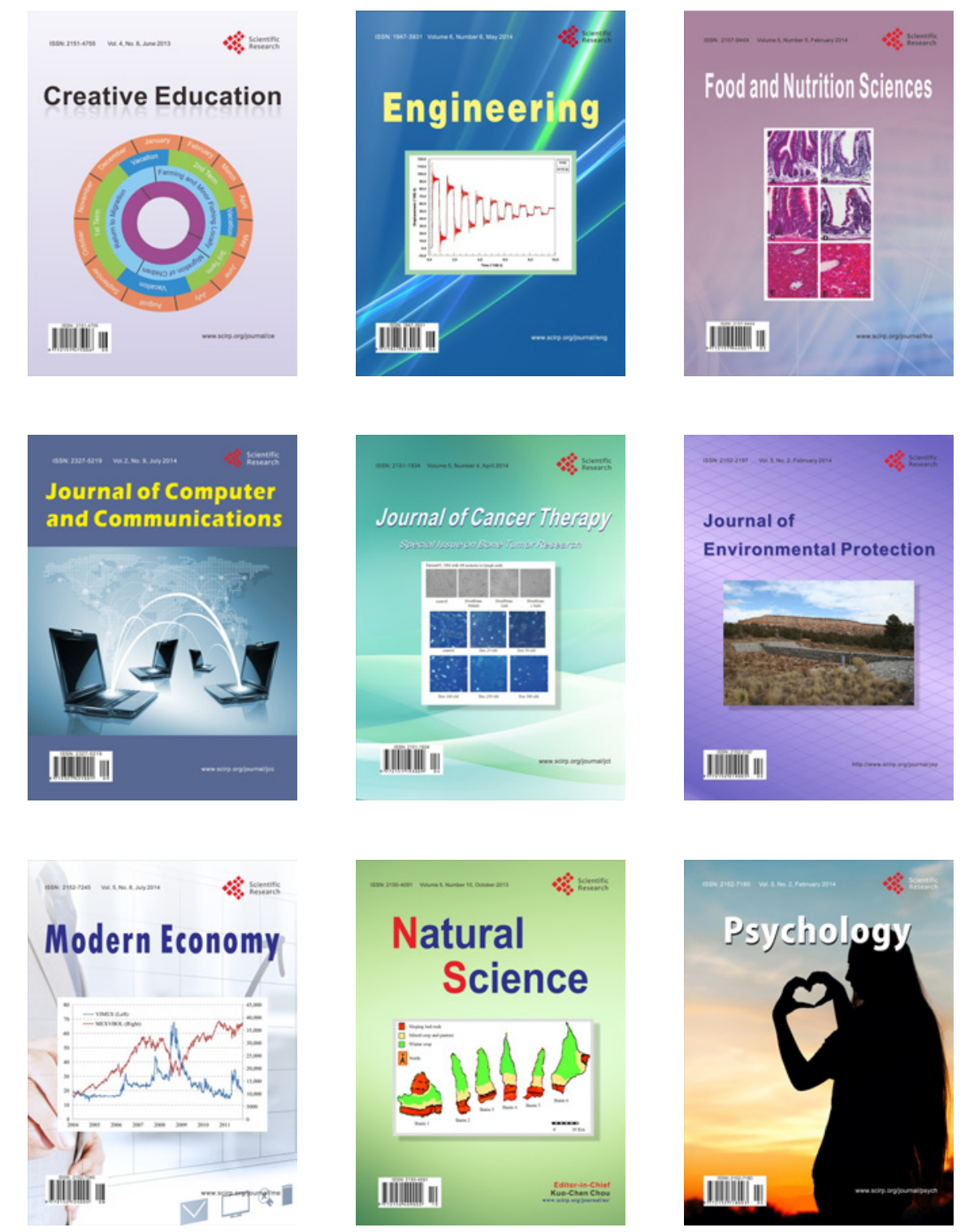